\title{
Formulations, characterization, in vitro and ex vivo release of Ephedra extract from topical preparations using dialysis cellulose membrane and natural rabbit skin
}

\author{
Rahman Gul1,2,3, Syed Umer Jan ${ }^{1,4}$, Mahmood Ahmad ${ }^{5}$, Syed Faridullah", Muhammad Akhtar ${ }^{5}$ \\ ${ }^{1}$ Faculty of Pharmacy, University of Balochistan, Quetta, Pakistan \\ ${ }^{2}$ Department of Health, Government of Balochistan, Pakistan \\ ${ }^{3}$ Balochistan University of Information Technology, Engineering \& Management Sciences (BUITEMS), Quetta, Pakistan \\ ${ }^{4}$ College of Pharmacy, University of Texas at Austin, Austin, TX, USA

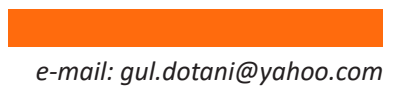

${ }^{5}$ Faculty of Pharmacy and Alternative Medicine, The Islamia University of Bahawalpur, Pakistan

\section{ABSTRACT}

Ephedra is herbal medicine used in the treatment of many diseases, especially asthma and urticaria. The aim of this study was to formulate topical formulations as a microemulsion, a gel and an ointment containing the Ephedra extracts of (E. Intermedia), collected from Balochistan, Pakistan and to evaluate their isolation, characterization and in vitro and ex vivo permeability release using markers. High performance liquid chromatography (HPLC) was used for the quantification of markers, and in vitro and ex vivo studies were done by Franz diffusion cells. The kinetics release and permeability was checked by cuprophan dialysis membrane and natural rabbit skin to justify their stability for topical use. Of the three formulations, release behavior of microemulsion and gel was almost the same, and the ointment showed slow release. The cellulose membrane showed faster release than the rabbit skin; this arrangement can be shown as microemulsion > gel > ointment. However, Korsmeyer-Peppas release kinetics for the three formulations were observed for the membranes. This study demonstrates that it is necessary to assess the impact of release and permeability patterns of different formulations. In vitro and ex vivo experiments can be utilized to develop formulations of traditional medicines.

KEYWORDS: Topical formulations; HPLC; Franz diffusion cells; cuprophan dialysis membrane; rabbit skin; release kinetics

\section{INTRODUCTION}

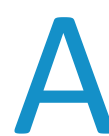
sthmatic diseases are spreading in our society; among them, bronchial asthma and urticaria (hives) are the most common diseases in cold climate countries. Many herbal types of remedies are used as household treatments for asthma and urticaria. In Asia, Ephedra (E. intermedia) is used to treat asthma and urticaria. Ephedra alkaloids are derived from the dried herbaceous stems of $E$. sinica stapf, E. intermedia Schrenk \& CA Meyer, or E. equisetina Bunge. It is also known as ma-huang, which has been commonly used as a traditional Chinese medicine since ancient times. The active constituents in Ephedra herbs are ephedrine alkaloids such as methylephedrine, ephedrine (E), and pseudoephedrine (PE), whose contents and compositions vary based on the plant types, growing conditions, and processing methods of the raw material $(1,2)$. Ephedra (E. intermedia) belongs to family Ephedraceae, and is a genus of no flowering plants belonging to the Gnetales, very near relatives of Angiosperms (3). Most of the 50 Ephedra species throughout the world have adapted as a shrub to moisture and desert conditions $(4,5)$. Three species are found in Pakistan. E. intermedia shrubs are always green and called ma-huang, and are locally known as "oman." Ma-huang (Ephedra herba) is resultant from the aerial parts of E. sinica Stapf, E. intermedia Schrenk, $E$. equisetina Bunge, and E. distachya $L$. It has been utilized medicinally as a stimulant, diaphoretic, and antiasthmatic $(6,7,8)$. It is a xerophytic shrub and grows in unfavorable soil and climatic conditions such as high temperature and high light (9). In most of the marketed drugs containing $\mathrm{E}$ and $\mathrm{PE}$, alkaloids are present in many species of Ephedra extracts. The best-recognized drug prepared from Ephedra is ma-huang, utilized in Chinese drugs for the treatment of nasal congestion, fever, and asthma (10). Ma-huang is also used as a respiratory sedative and cough treatment. Herbal mixtures having ma-huang in western health food stores are sold as

* Corresponding author. 
a nutritional supplement for claiming that they have assisting dietary and energizing value (11). Ma-huang was traditionally gained from dried stems of $E$. equisetina, $E$. sinica, and E. intermedia (12). They are found in the region of Iran, northwest India, and Pakistan (Balochistan). These shrub plants also showed antioxidant and antimicrobial activities (13-15). Ephedra basic compounds consist of the alkaloids $E$ and $P E$ and phenols (16). The stem consists of overall 1-3\% alkaloids, having E comprising $30-70 \%$ of the total, depending on all the species and types of Ephedra plant. Ephedrine activates the central nervous system, increases blood pressure, dilates the bronchial tubes, and increase the pulse rate. Pseudoephedrine is used for the relief of nasal congestion in its synthetic form (17-19). The herb Ephedra, or ma-huang as the aerial part of the herb is identified in conventional Chinese medicine, is the oldest medicinal herbs mentioned in literature. Many recipes originating from Shokan ZatsubyoRon, a classical textbook of traditional Chinese medicine, are still used for the treatment of various diseases (e.g. asthma, cold, diaphoresis, flu, fever, headache, edema, arthralgia, eczema, and rheumatism) and as stimulant or diuretic. In China and India, E. sinica Staph and E. gerardiana Wallich have been used since old times. They are most commonly administered as a tea. Their sun-dried green stems are cut into pieces and boiled in water for half an hour. The use of Ephedra in traditional medicine is one of the oldest known to mankind.

In Japanese traditional herbal medicine (Kampo), E. sinica, $E$. equisetina Bunge, and $E$. intermedia Schrenk have been used as antitussive, expectorant, antipyretic, analgesic, and bronchodilator agents. They are still mentioned in the textbook, Japanese Pharmacopeia, and Japanese researchers demonstrated hypoglycemic activity of five glycans, ephedrans $A-E$, isolated from $E$. distachya $L$. (20). In southwest America, the species E. nevadensis S. Wats and E. trifurca Parry were used to brew "Mormon tea" to treat allergies and colds and as a stimulant. The use of the Ephedra herb dropped in European medieval medicine although it was well known during the Roman Empire (20). Ephedra species are found to ease symptoms caused by common cold, bronchitis, influenza, asthma, hay fever, flu, chills, fever, headaches, bone pains, nasal congestion, coughing, and sneezing. In Eastern medicine, stems of Ephedra (ma-huang) are an essential drug for the treatment of asthma. The World Health Organization defines the medicinal utility of Ephedra harvest for the cure of nasal decongestion caused by common cold and rhinitis and as a bronchodilator in the treatment of asthma. Pseudoephedrine is regularly utilized as decongestant in common cold products (21).
The objective of this study was to isolate and formulate three topical dosage forms, a microemulsion, a gel, and an ointment, utilizing Ephedra extracts to develop traditional medicine and increase its bioavailability. The extracts were subjected to evaluate their release from topical preparation using Franz cells, dialysis cellulose membrane, and natural rabbit skin.

\section{MATERIAL AND METHODS}

Pseudoephedrine $\mathrm{HCl}$ was chosen as the analytical standard for $E$. intermedia and was gifted from Merck Serono (Quetta, Pakistan). Wool fat, cetostearyl alcohol, and hard paraffin were purchased from Sigma Aldrich (St. Louis, MO, USA). Olive oil, CarbopolP934, and oleic acid were purchased from Merck KGaA (Darmstadt, Germany). Acetonitrile, methanol, disodium hydrogen phosphate, potassium dihydrogen phosphate, triethanolamine, and ethanol (95\%) were purchased from Caledon Laboratories Ltd (Georgetown, ON, Canada). Glacial acetic acid and polysorbate80 were purchased from Fisher Scientific (Hampton, NH, USA). Cuprophan dialysis cellulose membrane (hydrophilic, $128 \times 34-\mathrm{mm}$ sheet), were obtained from Medicell Membranes Ltd (London, England). All other chemicals used were commercially available products of high purity grade.

\section{Plant Materials}

The whole plant, Ephedra herba, was collected during June to August 2015 from Ziarat, Sherani and Kalat districts of Balochistan, and identified and authenticated by Prof. Dr. Rasool Baksh Tareen, Botany Department, University of Balochistan, Pakistan. The plants were dried at room temperature in the shade for about 10 days. Dried plant material was ground to a powder by mechanical mills and weighed.

\section{Extraction Procedure}

The extraction was done by the following method and extracts were analyzed by a thin layer chromatography (TLC) developing system. A 250-g sample of dry, powdered material was moistened with sodium carbonate dilute solution.

The mixture was soaked and dried in cold benzene (5.0 L) three times for 5-6 hours and filtered. The extracts were diluted with $5 \% \mathrm{HCl}$, three times equal volume, and clarified with the acid solution, with solid potassium carbonate added to the acid solution. The alkaloids were extracted with chloroform, and the chloroform layer was dried with anhydrous sodium sulphate. It was evaporated until dryness. The extracts alkaloid residue was yellow color (20.1 mg). 


\section{Separation of the Alkaloids}

A quantity of this residue $(20.1 \mathrm{mg})$ was dissolved in chloroform and applied with standard reference on a number of preparative TLC plates using silica gel Gf/254. The TLC plates were developed in mobile phase (n-Butanol: Acetic Acid: water; 40:10:50). The solvent reached $15 \mathrm{~cm}$ from the marked base line. Standard reference Rf PE, E and Ephedra test sample ET bands were observed under ultraviolet light at $254 \mathrm{~nm}$ and $366 \mathrm{~nm}$. Each band was separated and dissolved in methanol and filtered. Then, evaporation under a vacuum was done and get the residue of each alkaloids base $800 \mathrm{mg}(0.3 \%)$, and pass it through $\mathrm{HCl}$ gas to convert the Ephedra base into $\mathrm{PE} \mathrm{HCl}$ alkaloid.

\section{Phytochemical Screening}

The dried samples were subjected to analyze for alkaloids, flavonoids, tannin, saponins, carbohydrates, anthraquinones, and cardiac glycosides.

\section{HPLC Quantization of Pseudoephedrine Extracted from Ephedra}

Instrumentation

The HPLC method was performed using a system equipped with a DGU-AM 14 degasser, manual injector system, SPD-10 AVP UV-VIS detector, and Hypersil BDS C8 $(250 \times 4.6 \mathrm{~mm})$ column (Agilent Technologies, 1100 Series, USA with LC- 10AT VP pump). Chem Station series 2001-2005 was used for the data collection and data processes. The chromatographic conditions used for analysis were as follows: the mobile phase consisted of a mixed buffer solution $\mathrm{pH} \mathrm{5.3,} \mathrm{methanol,} \mathrm{and} \mathrm{acetonitrile}$ (ACN) $(100 \mathrm{~mL}+100 \mathrm{~mL}+800 \mathrm{~mL}$, respectively). The flow rate was $1 \mathrm{~mL} / \mathrm{min}$, injected volume $20 \mu \mathrm{L}$, and samples were detected by an ultraviolet-visible detector at a wavelength of $210 \mathrm{~nm}$.

\section{Preparation of Microemulsion}

The microemulsion was prepared by the method of Chen et al. (22). A surfactant and co surfactant mixture of polysorbate 80 and ethanol was mixed manually in a 2:1 ratio. A 4.6-g sample of surfactant mixture was added to $0.5 \mathrm{~g}$ of the oil (oleic acid) already weighed and properly mixed with the magnetic stirrer. Ephedra extracts $(0.5 \mathrm{~g})$ were added to the surfactant mixture and then to the oleic acid (oil) and stirred vigorously until completely dissolved. Finally, we added $4.4 \mathrm{~g}$ distilled water slowly under continuous stirring (1200 rpm) at room temperature.

\section{Preparation of Gel}

A gel was formulated by the method of Proniuk et al (23). Carbopol powder 934P (1 g) was gradually dissolved in
$50 \mathrm{~mL}$ distilled water under continuous stirring (1200 rpm) at ambient temperature. In the next step, plant extracts $(0.5 \mathrm{~g})$ were mixed in $10 \mathrm{~mL}$ ethanol and stirred until homogeneous. The plant extracts solution was added to the carbopol solution drop wise and stirred continuously. Olive oil $(2 \mathrm{~mL})$ was added to the final solution. Triethanolamine was added drop wise to initiate the gel and increase the $\mathrm{pH}$, and the $\mathrm{pH}$ was determined. The solution was stirred continuously while adding a sufficient amount of distilled water to reach $100 \mathrm{~mL}$ total volume and gel was obtained.

\section{Preparation of Ointment}

A simple BP ointment was formatted by the method of Marriot et al (24). First, $4.75 \mathrm{~g}$ hard paraffin was melted at $60^{\circ} \mathrm{C}$, to which $4.75 \mathrm{~g}$ wool fat was added, followed by 4.75 $\mathrm{g}$ cetostearyl alcohol. The prepared ointment was stirred and cooled at ambient temperature. Ephedra extracts $(5.0 \mathrm{~g})$ and white soft paraffin $(80.75 \mathrm{~g})$ were added, and we measured the characterization.

\section{Drug Content}

The drug content of all formulations was determined, an approximately 100-mg sample was dispensed in $100 \mathrm{~mL}$ mobile phase in a conical flask and stirred with the help of magnetic stirrer for 2 hours until completely dissolved. The solution was filtered through filter paper $(0.2 \mu \mathrm{m})$ and analyzed by a validated HPLC method at $210 \mathrm{~nm}$, and the drug concentration was calculated.

\section{Preparation of Rabbit skin for ex Vivo Studies}

Albino rabbit skin was used for ex vivo studies of Ephedra extracts. The rabbit was anesthetized with chloroform and the hair from its dorsal region was carefully shaved with the help of electric razor. We washed the skin with a cotton swab and left the animal for 24 hours, so the skin became normal. After the rabbit was sacrificed, we carefully excised the skin with the help of sharp blade. The epidermis was removed by dipping it in hot water of almost $60^{\circ} \mathrm{C}$. Then, we teased the dermis from the two layers of skin, and the two layers were separated and covered with aluminum foil until further use.

\section{In Vitro Study Protocol}

Franz diffusion cells apparatus (Perme Gear, USA) was used for in vitro and ex vivo studies of Ephedra extract across the artificial synthetic membrane and natural rabbit skin. The artificial synthetic cellulose membrane cuprophan dialysis membrane or albino natural rabbit skin was fixed properly in the donor and the receptor jacket of the Franz cell apparatus. Ethyl alcohol and phosphate buffer (25:75) was used as a receptor medium, and $12 \mathrm{~mL}$ of it 
was used in the receptor compartment. The upper donor compartment was filled with $1 \mathrm{~g}$ microemulsion, gel, and ointment. The temperature was maintained at $37^{\circ} \mathrm{C}$ in the receptor medium throughout the study. A $1-\mathrm{mL}$ sample was withdrawn from the receptor medium. The sampling intervals were at $0.5,1,2,3,4,5,6,12$, and 24 hours, and we replaced each sample with fresh medium having the same temperature. Recovered samples were analyzed by HPLC at $210 \mathrm{~nm}$ (25-27). To accommodate the slight variations in the six Franz cells, experiments were performed in triplicates.

\section{In Vitro Release Kinetic Studies of Ephedra}

The quantity of drug (in $\mathrm{mg}$ ) in the receptor sample medium was analyzed ( $0-24$ hours) by an HPLC technique, and the permeated amount of drug was identified and computed. The linearity regression analyses and the release parameters of the drug permeation for each formula were analyzed. The correlation coefficient $(r)$ was calculated for each formula by each kinetic equation to assess whether the drug release and permeation of the drug through the membrane and natural skin follows a zero order, first order, Higuchi, Korsmeyer-Peppas, or Hixon-Crowell diffusion release model. All calculations were carried out according to the following kinetics equations using a validated software program, DDSolver for Microsoft Excel 2007 (28).
Model

- Zero order

- First order

- Higuchi

- Korsmeyer-Peppas plot

- Hixon-Crowell

$$
\begin{aligned}
& \text { Equation } \\
& \mathrm{Q}_{\mathrm{t}}=\mathrm{Q}_{\mathrm{o}}+\mathrm{K}_{\mathrm{o}} \mathrm{t} \\
& \ln \mathrm{Q}_{\mathrm{t}}=\ln \mathrm{Q}_{\mathrm{o}}+\mathrm{K}_{1} \mathrm{t} \\
& \mathrm{Q}_{\mathrm{t}}=\mathrm{K}_{H} \mathrm{Vt}^{\mathrm{t}} \\
& \mathrm{Mt} / \mathrm{M} \infty=\mathrm{K}_{\mathrm{t}}{ }^{\mathrm{n}} \\
& \mathrm{Q}_{\mathrm{t}} / \mathrm{Q}_{\mathrm{O}}=\mathrm{K}_{\mathrm{k}} \mathrm{t}^{\mathrm{n}}
\end{aligned}
$$

\section{Statistical Analysis}

Wilks Lambda two-way analysis of variance (ANOVA) was used to evaluate the effect of dialysis cellulose membrane and natural rabbit skin using SPSS 18 software (IBM) (29). For comparison of the formulations, the $f_{2}$ factor analysis was used (30). The release data of all formulations were fit to the Korsmeyer-Peppas release kinetic model and then compared with one another. Flux (j) was calculated as $\mu \mathrm{g} / \mathrm{h} / \mathrm{cm}^{2}$ (31).

\section{RESULTS AND DISCUSSION}

\section{HPLC}

HPLC was used to deduct the PE alkaloid presence in the extracted Ephedra and its formulations. The result showed a retention time of $10.069 \mathrm{~min}$ for the standard and $10.135 \mathrm{~min}$ for the sample (Figure $1(\mathrm{~A})$ and (B)). The PE quantification result was $200 \mathrm{mg} / \mathrm{g}$ of the extracts, microemulsion was $98.20 \%$, gel was $97.57 \%$, and ointment was $97.33 \%$.as shown in Table 1.
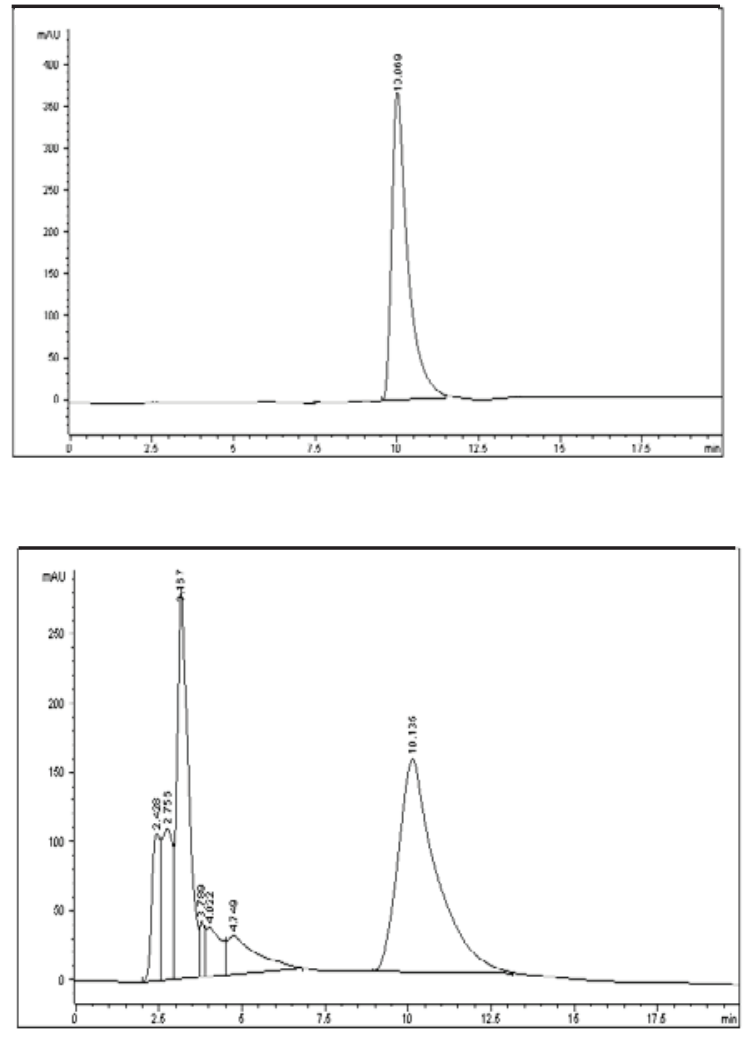

Figure 1. Retention time for (A) standard pseudoephedrine, 10.069 min.; (B) Ephedra extract, $10.135 \mathrm{~min}$.

Table 1. Percentage of Drug Content in Formulations

\begin{tabular}{|c|c|}
\hline Formulations & \% Drug Content \\
\hline Microemulsion & $98.20 \%$ \\
\hline Gel & $97.57 \%$ \\
\hline Ointment & $97.33 \%$ \\
\hline
\end{tabular}

Comparison of Three Semisolid Dosage Forms of Ephedra Samples (1 g) of topical formulations containing Ephedra $(\mathrm{PE})$ were analyzed using dialysis cellulose membrane and natural rabbit skin. Figure 2(A) and (B) shows the release profiles of $\mathrm{PE}$ from three dosage forms. The micro emulsion and gel showed visible release and permeable patterns from cellulose membrane and natural rabbit skin, and both formulations showed similarity in their release and permeability pattern, as shown in Table 2 $\left(f_{2}=55\right.$ and 57 before $6 \mathrm{~h}$ and $f_{2}=41$ and 55 up to $24 \mathrm{~h}$, respectively). The release and permeability data fit well into a Korsmeyer-Peppas model. The ointment showed dissimilarity in release and permeability in rabbit skin and cellulose membrane; the $f_{2}$ values were below 50 when compared with the micro emulsion and gel formulations. A Korsmeyer-Peppas release model and permeability from the ointment was observed when the dialysis cellulose membrane and natural rabbit skin was used. 
(A)

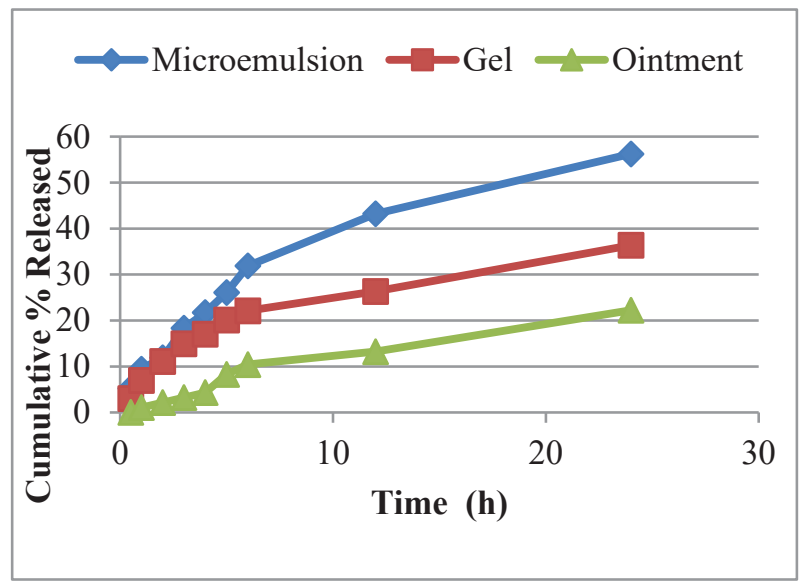

(B)

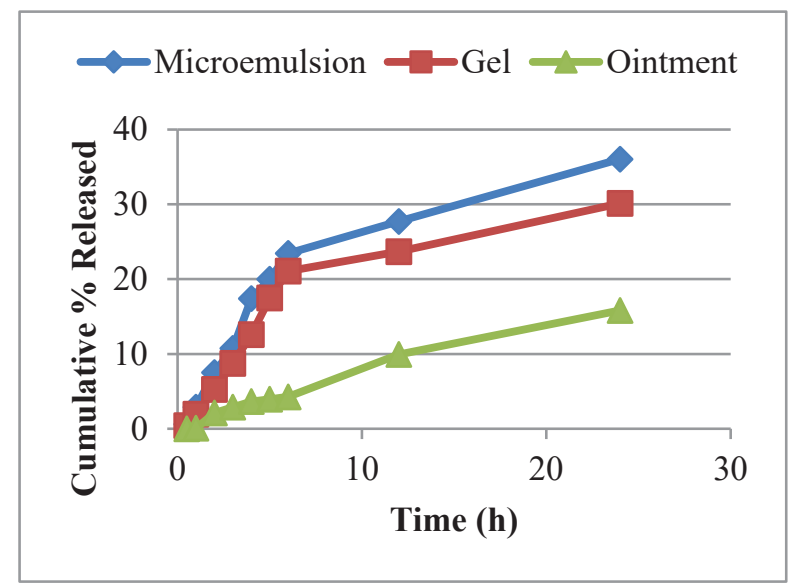

Figure 2. Comparison of the release profiles of pseudoephdrine from three topical dosage forms containing Ephedra using (A) dialysis cellulose membrane and (B) natural rabbit skin.

Table 2. Factor $f_{2}$ Analysis for Three Dosage Forms of Ephedra (0-24 h)

\begin{tabular}{|c|c|c|c|c|}
\hline \multirow{2}{*}{ Formulations } & \multicolumn{2}{|c|}{$\begin{array}{c}\text { Dialysis cellulose } \\
\text { membrane }\end{array}$} & \multicolumn{2}{c|}{$\begin{array}{c}\text { Natural rabbit } \\
\text { skin }\end{array}$} \\
\cline { 2 - 5 } & $\mathbf{0 - 6} \mathbf{~ h}$ & $\mathbf{0 - 2 4} \mathbf{~ h}$ & $\mathbf{0 - 6} \mathbf{~}$ & $\mathbf{0 - 2 4} \mathbf{~}$ \\
\hline Microemulsion vs. Gel & 55 & 41 & 57 & 55 \\
\hline Microemulsion vs. Ointment & 38 & 27 & 44 & 36 \\
\hline Gel vs. Ointment & 44 & 39 & 48 & 42 \\
\hline
\end{tabular}

These data indicate that the membrane nature had a considerable impact on the release and permeability of the tested formulations.

Assessment of release and permeability patterns from topical formulations is not novel, but few studies investigate the traditional medicinal plants and active assessments of the markers. Traditional classes of topical formulations were prepared such as micro emulsion, gel, and ointment. The amount of drug released from different formulations (microemulsion, gel, and ointment) using cuprophan dialysis cellulose membrane is illustrated in Table 3, and the natural rabbit skin is illustrated in Table 4. It is clear that the amount of PE released from different formulations by using cuprophan cellulose membrane and rabbit skin can be arranged according to the following descending order: microemulsion > gel > ointment This similarity between both in vitro and ex vivo results illustrates the value of administrating PE as a topical dosage form. As Shown in Figure $1 A$ and $B$, at least two distinct release profiles for the microemulsion and gel were obvious within $24 \mathrm{~h}$. As shown in Table 3, the release of drug from micro emulsion and gel via cellulose membrane was $56.24 \%$ and $36.36 \%$ after $24 \mathrm{~h}$, respectively. It is clear that the amount of PE released from different formulations by using cellulose membrane was high and may be due to the presence of polysorbate 80 and ethanol as enhancer. The release of drug from gel at the first 0.5 -hr interval may be due to the gel swell-up, and its first burst may increase penetration of the drug and then drop via cellulose membrane. The drug release from ointment through cellulose membrane was $22.33 \%$ at $24 \mathrm{~h}$. The slow release of the drug may be due to affinity of the drug to the base and its viscosity thereby decreasing the proportion of drug release. After $24 \mathrm{~h}$, the drug release through cellulose membrane follows the Korsmeyer-Peppas plot for the three formulations. The drug release from natural rabbit skin in Table 4 shows that the microemulsion concentration of the drug after $24 \mathrm{~h}$ was $35.5 \%$. The gel drug release concentration after $24 \mathrm{~h}$ was $30.13 \%$. Although the drug release from the ointment was $15.82 \%$ at the same time point, the slow release may be due to strong affinity of the drug to the base, decreasing the drug release. Furthermore, this slow release may be due to the absence of the oily phase in this formulation. Drug release through rabbit skin for the three formulations follows the Korsmeyer-Peppas plot. Table 5 shows that the flux (j) was calculated for all dosage forms. We mostly used an ethanol solvent as a receptor medium for the semisolid dosage form. Higher alcohol content in the medium increases the drug release content between the donor compartment and the receptor $(26,27)$. We showed that a $30 \%$ ethanol medium was sufficient to maintain diffusional sink conditions while not adversely affecting the integrity of the dosage form.

Drug release through the rabbit skin was lower than the cellulose membrane. However, the penetration of PE across cellulose membrane was more than the natural rabbit skin, which could be due to the above-mentioned reason or the rabbit skin used in this study was thicker and its pore size was smaller, which would allow less drugs to penetrate the skin compared to the dialysis cellulose 
Table 3. Pseudoephedrine Release From Three Formulations Using Dialysis Cellulose Membrane and Its Kinetic Data

\begin{tabular}{|c|c|c|c|c|c|c|c|c|c|c|}
\hline \multirow{2}{*}{$\begin{array}{c}\% \text { of drug } \\
\text { Released after } \\
24 \mathrm{~h}\end{array}$} & \multirow{2}{*}{ Base } & \multicolumn{9}{|c|}{ Amount of drug release in $\mathrm{mg} / 1.5 \mathrm{~cm}^{2}$ after the following time intervals } \\
\hline & & $0.5 \mathrm{~h}$ & $1 \mathrm{~h}$ & $2 \mathrm{~h}$ & $3 \mathrm{~h}$ & $4 \mathrm{~h}$ & $5 \mathrm{~h}$ & $6 \mathrm{~h}$ & $12 \mathrm{~h}$ & $24 \mathrm{~h}$ \\
\hline 56.24 & Microemulsion & 0.1052 & 0.1884 & 0.2385 & 0.3666 & 0.4347 & 0.5217 & 0.6377 & 0.8643 & 1.1248 \\
\hline 36.36 & Gel & 0.6090 & 0.1393 & 0.2219 & 0.2987 & 0.3402 & 0.402 & 0.4422 & 0.5267 & 0.7272 \\
\hline 22.33 & Ointment & 0.0003 & 0.0213 & 0.0426 & 0.0647 & 0.0865 & 0.1657 & 0.2083 & 0.2647 & 0.4466 \\
\hline \multicolumn{11}{|c|}{$\mathbf{R}^{2}$ (coefficient of determination) } \\
\hline \multicolumn{2}{|c|}{ Formulations } & $\begin{array}{l}\text { Zero } \\
\text { order }\end{array}$ & First order & Higuchi & \multicolumn{2}{|c|}{ Hixon-Crowell } & \multicolumn{2}{|c|}{ Korsmeyer-Peppas } & \multicolumn{2}{|c|}{ Best fitting model } \\
\hline \multicolumn{2}{|c|}{ Microemulsion } & 0.6815 & 0.6850 & 0.9782 & \multicolumn{2}{|c|}{0.6839} & \multicolumn{2}{|c|}{0.982} & \multicolumn{2}{|c|}{ Korsmeyer-Peppas } \\
\hline \multicolumn{2}{|c|}{ Gel } & 0.4747 & 0.4777 & 0.9725 & \multicolumn{2}{|c|}{0.476} & \multicolumn{2}{|c|}{0.9766} & \multicolumn{2}{|c|}{ Korsmeyer-Peppas } \\
\hline \multicolumn{2}{|c|}{ Ointment } & 0.9239 & 0.9243 & 0.8665 & \multicolumn{2}{|c|}{0.9180} & \multicolumn{2}{|c|}{0.9242} & \multicolumn{2}{|c|}{ Korsmeyer-Peppas } \\
\hline
\end{tabular}

Table 4. Pseudoephedrine Release From Three Formulations by Natural Rabbit Skin and Its Kinetic Data

\begin{tabular}{|c|c|c|c|c|c|c|c|c|c|c|}
\hline \multirow{2}{*}{$\begin{array}{c}\% \text { of drug } \\
\text { Released after } \\
24 \mathrm{~h}\end{array}$} & \multirow{2}{*}{ Base } & \multicolumn{9}{|c|}{ Amount of drug release in $\mathrm{mg} / 1.50 \mathrm{~cm}^{2}$ after the following time intervals } \\
\hline & & $0.5 \mathrm{~h}$ & $1 \mathrm{~h}$ & $2 \mathrm{~h}$ & $3 \mathrm{~h}$ & $4 \mathrm{~h}$ & $5 \mathrm{~h}$ & $6 \mathrm{~h}$ & $12 \mathrm{~h}$ & $24 \mathrm{~h}$ \\
\hline 35.5 & Microemulsion & 0.0124 & 0.0582 & 0.1506 & 0.2151 & 0.3480 & 0.4001 & 0.4688 & 0.5880 & 0.7000 \\
\hline 30.13 & Gel & 0.0086 & 0.0388 & 0.1055 & 0.1751 & 0.2517 & 0.3496 & 0.4217 & 0.4737 & 0.6026 \\
\hline 15.82 & Ointment & 0.0002 & 0.0016 & 0.0422 & 0.0577 & 0.0728 & 0.079 & 0.0855 & 0.1989 & 0.3164 \\
\hline \multicolumn{11}{|c|}{$\mathbf{R}^{2}$ (coefficient of determination) } \\
\hline \multicolumn{2}{|c|}{ Formulations } & $\begin{array}{l}\text { Zero } \\
\text { order }\end{array}$ & First order & Higuchi & \multicolumn{2}{|c|}{ Hixon-Crowell } & \multicolumn{2}{|c|}{ Korsmeyer-Peppas } & \multicolumn{2}{|c|}{ Best fitting model } \\
\hline \multicolumn{2}{|c|}{ Microemulsion } & 0.6117 & 0.6140 & 0.9229 & \multicolumn{2}{|c|}{0.6132} & \multicolumn{2}{|c|}{0.9249} & \multicolumn{2}{|c|}{ Korsmeyer-Peppas } \\
\hline \multicolumn{2}{|c|}{ Gel } & 0.6316 & 0.6380 & 0.9019 & \multicolumn{2}{|c|}{0.6373} & \multicolumn{2}{|c|}{0.9070} & \multicolumn{2}{|c|}{ Korsmeyer-Peppas } \\
\hline \multicolumn{2}{|c|}{ Ointment } & 0.9742 & 0.9744 & 0.8447 & \multicolumn{2}{|c|}{0.9743} & \multicolumn{2}{|c|}{0.9869} & \multicolumn{2}{|c|}{ Korsmeyer-Peppas } \\
\hline
\end{tabular}

membrane. More studies are needed to determine if the observed effects were only an effect of pore size, enhancer, or if the nature of the membrane material also contributed to the discriminatory power.

Table 5. Flux Values of Formulations

\begin{tabular}{|c|c|c|}
\hline Formulations & $\begin{array}{c}\text { Dialysis cellulose } \\
\text { membrane } \\
\mu \mathrm{g} / \mathrm{cm}^{2} / \mathrm{h}\end{array}$ & $\begin{array}{c}\text { Natural rabbit skin } \\
\mu \mathrm{g} / \mathrm{cm}^{2} / \mathrm{h}\end{array}$ \\
\hline Microemulsion & 1.346 & 0.700 \\
\hline Gel & 0.79 & 0.760 \\
\hline Ointment & 0.656 & 0.641 \\
\hline
\end{tabular}

\section{CONCLUSION}

This research work demonstrated that in vitro and ex vivo release experiments using Franz cells were effectively applied to traditional medicinal extracts. The micro emulsion and gel showed similar release rates through dialysis cellulose membrane and natural rabbit skin. The ointment showed a slower rate of drug release through dialysis cellulose membrane and natural rabbit skin.
The statistical data showed that both dialysis cellulose membrane and rabbit skin had a significant impact on PE release, and it could be used for further studies. It was concluded that in vitro and ex vivo diffusion cell experiments can be utilized to develop improved formulations of traditional medicines.

\section{ACKNOWLEDGMENTS}

The authors would like to thank the Higher Education Commission of Pakistan for financial support, Health Department Government of Balochistan (for study leave), and the faculty of Pharmacy \& Alternative Medicine at the Islamia University of Bahawalpur for support to complete this research.

\section{CONFLICT OF INTEREST}

The authors have no conflict of interest in relation to the publication of this manuscript.

\section{REFERNCES}

1. Haller, C. A.; Duan, M.; Benowitz, N. L.; Jacob, P., III. Concentrations of Ephedra alkaloids and caffeine in commercial dietary supplements. J. Anal. Toxicol. 2004, 8, 145-151. DOI: 10.1093/ 
jat/28.3.145.

2. Hong, H.; Chen, H. B.; Yang, D. H.; Shang, M. Y.; Wang, X.; Cai, S.Q.; Mikage, M. Comparison of contents of five ephedrine alkaloids in three official origins of Ephedra herb in China by high-performance liquid chromatography. J. Nat. Med. 2011, 65, 623-628. DOI: 10.1007/s11418-011-0528-8.

3. Friedman, W.E. The evolution of double fertilization and endosperm: an historical perspective. Sex. Plant Reprod. 1998, 11, 6-16. DOI: 10.1007/s004970050114.

4. Pearson, H. H. W. Gnetales. Cambridge: London, England, 1929.

5. Caveney, S.; Charlet, D. A.; Freitag, H.; Maier-Stolte, M.; Starratt, A. N. New observations of the secondary chemistry of world Ephedra (Ephedraceae). Am. J. Bot. 2001, 88, 1199-1280. DOI:10.2307/3558330.

6. Gul, R., Jan.U.S., Faridullah, S., Sherani, S., Jahan, N. Preliminary phytochemical screening, quantitative analysis of alkaloids, and antioxidant activity of crude plant extracts from Ephedra intermedia indigenous to Balochistan. Sci. World J. 2017; 1-7. DOI: $10.1155 / 2017 / 5873648$.

7. Huang, T. K. Handbook of composition and Pharmacological Action of commonly used traditional Chinese medicine (II). Chinese Medicine Technology Press, Beijing, China 1994, 16241631.

8. Bensky, D.; Gamble, A.; Kaptchuck, T. Chinese Herbal Medicine: Materia Medica. Eastland Press: Seattle, WA.1986, 32-40.

9. Freitag, H.; Maier-Stolte, M. The Ephedra-species of P. Forsskal: identity and typification. Taxon, 1989, 34, 545-556. DOI: 10.2307/1222629.

10. Zhu, Y. P. Chinese Materia Medica: Chemistry, Pharmacology and Applications. Harwood Academic: Amsterdam, Netherlands. 1998.

11. White, L. M.; Gardner, S. F.; Gurley, B. J.; Marx, M. A.; Wang, P. L.; Estes, M. Pharmacokinetics and cardiovascular effects of ma huang (Ephedra sinica) in normotensive adults. J. Clin. Pharmacol. 1997, 37, 116-122. DOI: 10.1002/j.1552-4604.1997.tb04769.x.

12. Qazilbach, N. A. Pakistan Ephedra. Pharmacologische Weekblad 1971, 106, 345-349.

13. Parsaeimehr, A.; Sargsyan, E.; Javidnia, K. A comparative study of the antibacterial, antifungal and antioxidant activity and total content of phenolic compounds of cell cultures and wild plants of three endemic species of Ephedra. Molecules 2010, 15, 16681678. DOI: 10.3390/molecules15031668.

14. Bagheri Gavkosh, S.; Bigdeli, M.; Shams-Ghahfarokhi, M.; Razzaghi-Abyaneh, M. Inhibitory effects of Ephedra major host on Aspergillus parasiticus growth and aflatoxin production. Mycopathology 2009, 5, 249-255. DOI: 10.1007/s11046-0099220-x.

15. Hollander, J. L.; Vander Wall, S. B. Dispersal syndromes in North American Ephedra. Int. J. Plant Sci. 2009, 170 (3), 323-330. DOI: 10.1086/596334.

16. Nawwar, M.; Barakat, H. H.; Buddrust, J.; Linscheidt, M. W. Alkaloid, lignan and phenolic constituents of Ephedra alata. Phytochemistry 1985, 24, 878-879. DOI: 10.1016/S0031-9422(00)84920-1.
17. Ganzera, M.; Lanser, C.; Stuppner, H. Simultaneous determination of Ephedra sinica and Citrus aurantium var. amara alkaloids by ion pair chromatography. Talanta 2005, 4, 889-894. DOI: 10.1016/j. talanta.2004.12.045.

18. Inoko, A.; Kakiuchi, N.; Yoshimitsu, M.; Cai, S. Q.; Mikage, M. Ephedra Resource in Sichuan and Yunnan Provinces 2007. Biol. Pharm. Bull. 2009, 32,1621-1623. DOI: 10.1248/bpb.32.1621.

19. Kitani, Y.; Zhu, S.; Omote, T.; Tanaka, K.; Batkhuu, J.; Sanchir, C.; Fushimi, H.; Mikage, M.; Komatsu, K. Molecular Analysis and Chemical Evaluation of Ephedra Plants in Mongolia. Biol. Pharm. Bull. 2009, 32 (7), 1235-1243. DOI: 10.1248/bpb.32.1235.

20. Abourashed, E. A.; El-Alfy, A. T.; Khan, I. A.; Walker, L. Ephedra in perspective - a current review, Phytother. Res. 2003, 17, 703712. DOI: $10.1002 /$ ptr.1337.

21. Guifeng, J.; Chen, R.; Loran, C. Quantitative Analysis of Pseudoephedrine Tablets by UHPLC/MS. Application Note: 419, Thermo Fisher Scientific: San Jose, CA, USA. 2008.

22. Chen, H.; Chang, X.; Du, D.; Li, J.; Xu, H.; Yang, X. Nanoemulsionbased hydrogel formulation of ibuprofen for topical delivery. Int. J. Pharm. 2006, 315, 52-58. DOI: 10.1016/j.ijpharm.2006.02.015.

23. Proniuk, S.; Dixon, S. E.; Blanchard, J. Investigation of the utility of an in vitro release test for optimizing semisolid dosage forms. Pharm. Dev. Technol. 2001, 6 (3), 469-476. DOI:1 0.1081/PDT100002255.

24. Marriott, J.F.; Wilson, K. A.; Langley, C. A.; Belcher, D. Pharmaceutical Compounding and Dispensing; Pharmaceutical Press: London, 2006; p 162. ISBN 9780853697008.

25. Ueda, C, T.; Shah, V. P.; Derdzinski, K.; Ewing, G.; Flynn, G.; Maibach, H.; Marques, M.; Rytting, H., Shaw, S., Thakker, K.; Yacobi, A. Topical and transdermal drug products. Pharm. Forum 2009, 35 (3), 750-764.

26. Shah, V. P.; Elkins, J. S.; Williams, R. L. Evaluation of the test system used for in vitro release of drugs for topical dermatological drug products. Pharm. Dev. Technol. 1999, 4 (3), 377-385.

27. Shah, V. P.; Williams, R. L. Importance of In Vitro Drug Release. In Topical Drug Bioavailability, Bioequivalence, and Penetration; Springer: New York, NY, 2014, pp 61-67. DOI: 10.1007/978-14939-1289-6_4.

28. Zhang, Y.; Huo, M.; Zhou, J. DD Solver: an add -in program for modeling and comparison of drug dissolution profiles. AAPS $J$. 2010, 12 (3), 263-271. DOI: 10.1208/s12248-010-9185-1.

29. Yuksel, N.; Kanik, A. E.; Baykara, T. Comparison of in vitro dissolution profile by ANOVA-based, model-dependent and -independent methods. Int. J. Pharm. 2000, 209 (1-2), 57-67.

30. Gohel, M. C.; Sarvaiya, K. G.; Mehta, N. R.; Soni, C. D.; Vyas, V. U.; Dave, R. K. Assessment of similarity factor using different weighting approaches. Dissolution Technol. 2005, 12 (4), 22-27. DOI: 10.14227/DT120405P22.

31. Kreilgaard, M.; Pederson, E. J.; Jaroszewaski, J. W. NMR characterization and transdermal drug delivery potential of microemulsion system. J. Control. Release 2000, 69 (3), 421-433. DOI: 10.1016/S0168-3659(00)00325-4.elps.200500002. 